\title{
Peculiarities of Modern Street Addressing System toward to Implementation of the Smart City Conception
}

\author{
Dmitriy Gakh \\ Institute of Control Systems \\ Bakhtiyar Vahabzadeh str. 9 \\ Baku, Azerbaijan \\ Email:dgakh@sinam.net
}

\begin{abstract}
Implementation of Smart City conception is direction of developing many modern cities. Rapid urbanization leaded to constant increasing urban population. At the same time technological growth is cause of increasing of density and complexity of urban infrastructure. Street Addressing system is an essential component of city management, quality of citizens' life, and other spheres of city's economy.

This paper considers peculiarities of Street Addressing system from human and technologies perspectives to be an essential part of the Smart Cities concept implementation.
\end{abstract}

\section{INTRODUCTION}

$\mathrm{S}$ treet Addressing (SA) system is an essential component of the city infrastructure. All problems concerning the SA are not currently reflected by proper research or sufficiently described. Such lack is caused by several factors which include, first of all, the shortage of SA in cities of poor countries and the spontaneous growth of urbanization and technosphere. The cities try to solve serious problem in urban management and adopt or upgrade the SA (by implementing the SA program) according to well-known and established methodologies.

However due to spontaneous growth of technologies, these methodologies do not consider new requirements and trends in required extent. The lack of research and resources is observed especially in SA issues relating to implementation of conception of so-called Smart City (SC). This lack is result of fact that the SC conception is young - publications about smart cities started to explode in 2012 [1].

There are several solid methodologies, proposed by the World Bank for implementing the SA programs, aimed for building or upgrading the SA in different cities [2]. These methodologies were based on practical research and implementation of SA programs in dozen of inhabited areas. At the same time the World Bank experts consider SA as a crucial component in initiatives to develop SC [3].

More and more cities are embarking on SA programs [3]. But almost all these programs are not SC oriented. There are several reasons why many cities do not focus on the SC concept in SA programs. On the one hand, there is no methodology for building/updating SA for SC. On the other hand, it seems that ICT is the solution of existing problems, and at the moment the issues of creating SA for ICT needs and, accordingly, for SC is not urgent. The absence of SC defini- tion also creates obstacles to deeply consider it in SA programs.

SA program is complex, expensive, and fundamental: it is city-wide, impacts many urban services, and quality of citizens' life. A look to the future and taking into consideration features of SC can help build SA that would be convenient for developing SC and use of its abilities completely. This paper introduces determination and definition of SA peculiarities that can be used for planning, implementing, and maintaining the SA system with the focus on implementation of SC conception (or shortly SA for SC).

The peculiarities of SA for SC are based on literature analyses, practical experience of developing the SA for Kabul (6.5 mln. inhabitants' area, Afghanistan) [4], [5] and developing the Geographical Information System for Baku (4.6 mln. inhabitants' area, Azebaijan / http://www.gomap.az). The research includes synthesis of knowledge in urban management, engineering, and ICT.

\section{What is Smart City ?}

The first question that should be answered is "what is SC?". Cities worldwide play a prime role in social and economic aspects, and have a huge impact on the environment [6]. SC seems to be a direction to where modern cities are being developed, but the final stage of this development is still unclear. Two main drivers are underlying this development: solution of existing problems and applying the new abilities due to availability of new technologies. And as the study shows, Information and Communication Technologies (ICT) are the key players. Meanwhile researchers note that SC should satisfy to people and community needs [6].

Cities worldwide have started looking for solutions to enable transportation linkages, using mixed land, and highquality urban services with long-term positive effects on the economy. Many of the new approaches related to urban services have been based on harnessing technologies, including ICT, helping create what some call "Smart Cities" [6].

There is no established definition of what a SC is. The SC concept has been developed in three main areas: Academic, Industrial, and Governmental. Although the meaning of Smart City is not settled yet, there is an agreement on the significant role of ICTs in smart urban development [7]. ICT application requires digitalization of data and procedures 


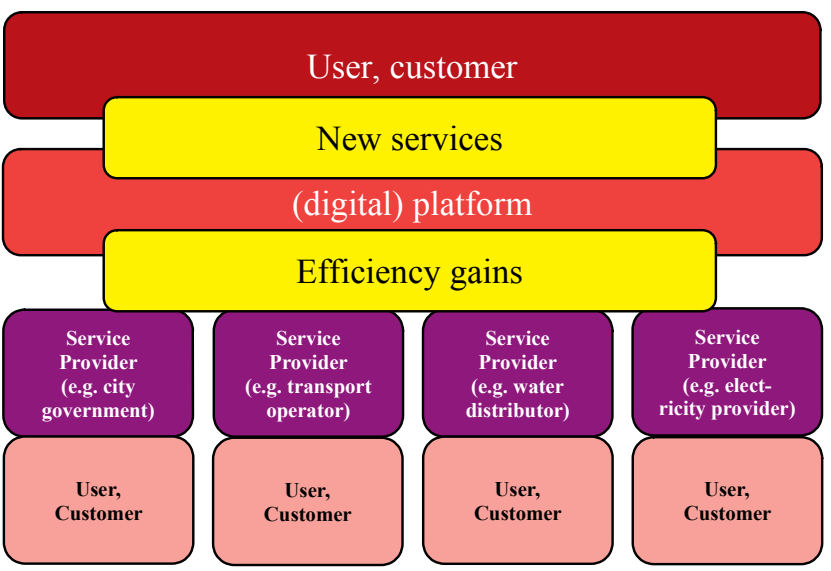

Fig 1. The potential of digitalization for cities

that brings opportunities to introduce new services and get efficiency gains. The potential of digitalization for cities is presented by Fig. 1.[1]

Several terms, such as "Digital", "Instrumented", "Interconnected", "Intelligent" are used to describe "Smart City" phenomena [8]. At the same time the SC concept is not limited to the diffusion of ICT, but it looks at people and community needs. Diffusion of ICT in cities has to improve the way every subsystem operates, aiming to enhance the quality of life [6].

Scientists from different disciplines contribute research of $\mathrm{SC}$. As a result, $\mathrm{SC}$ is presented from different perspectives, such as engineers' perspective, economists' perspective, innovation economists' perspective, public managers' perspective, sociologists' perspective, human ecologists' perspective. The following practices, all of which come under the "Smart City" label can be identified: Smart Transportation, Smart Environment, Smart Energy, Smart Water, Smart Building, Smart Safety and Security, Smart Health Care, Smart Government/City-Services, Smart Participation, and Connectivity [1].

According to [9], the following components constitute SC:

- Inter-operability of systems (key component);

- Sustainability (energy and water efficiency);

- City-wide connectivity;

- Security;

- Effective transportation;

- Development of private/public partnerships.

There are also several mature models allowing to assess how "smart" the city is. Low level of maturity of the SC, the lack of sufficient and real-time data, and the lack of standardization in previous years hampered development of such models. Citizens are considered as "prosumers" of geotagged data and content affecting cities' everyday norms and interactions [10].

The study shows that SC can be considered as a sociotechnical system. This statement is studied in details in [8]. In this way SA for SC should be considered from two perspectives: to serve people and to serve technologies. How- ever, it should be mentioned that the technologies are intended to serve people and can support SA. So, we can say that considering SC as a socio-technical system is the solid starting point for determination and formulation of the SA peculiarities.

\section{What is Street Addressing ?}

Although SA seems as well-known and well-studied conception that does not require research, this is not true. First of all, as mentioned above, there are many cities worldwide that are implementing SA program [3]. Experience gained in these programs forms solid base for research. Secondly, implemented SA programs are targeted mainly to solve existing problems, but not focus to the future technologies. Indeed, the absence of SA has greater negative effect to the urban economy than positive impact that could bring orientation towards the SC. Cost of SA and planning the faster Return of Investments (ROI) are additional factors leading to avoid such orientation.

\section{A. Purpose of Street Addressing}

SA is quite old and well-established conception. But conception of SC introduces not only new requirements to SA, but also new abilities to its utilization/maintenance.

The main purposes of SA are to [2]:

- enable people to get around the city more easily;

- facilitate the delivery of emergency health, fire, and police services;

- locate urban facilities;

- improve planning and managing municipal services;

- assist with urban planning and programming of investments;

- improve local tax collection;

- enable utility concessionaires to manage their networks more effectively.

These purposes can be grouped as determination of current location and determination of the delivery point.

Development of ICT and other modern technologies introduces new challenges, i.e.:

- Development of Geographical Positioning Systems (GPS), Geographical Information Systems (GIS) and Geocoding services introduces alternative ways of determination the location;

- Decentralization of city services has led to emergence of a wide range of small-sized fixtures, such as ATMs, POS terminals, electricity/water/gas distribution units, and so on. SA should be able to address these facilities (World Bank methodologies consider addressing such fixtures [2]). Many SA systems do not intend to address such small facilities;

- Increasing the density of buildings, premises, facilities etc. leads to raise of volatility (for example joining several sale points to one, then in some years divide up them back) that require SA to be 
updated according to the changes. Many SA systems are unable to be updated and reflect real conditions in time;

- Automation of services, such as delivery, transportation, and so on requires integration of SA with the computer systems. Mismatch of SA data with the real situation leads to the loss of computer systems effectiveness.

Such challenges demonstrate the necessity and on the other hand abilities to implement SA programs taking into consideration development of ICT-related technologies, density and granularity of city infrastructure, and proper quality assurance.

Urban information database, which, in conjunction with a SA plan and a street index, can be used for various applications and benefit the population as a whole, local governments, and the private sector. One of actual case studies of SA application is monitoring of epidemics in Maputo, Mozambique [2]. It is obvious that involvement of ICT in SA applications leads to significant improvements.

Implementation of ICT in modern cities creates new environment to process city-related data. Optimization of physical city infrastructure, growth, concentration, and decentralization of this infrastructure introduce new requirements to identify location of the infrastructure units (urban fixtures). An example of problems relating to increase of density in city areas are issues relating to the street vendors. In poor areas problems with street vendors are complex and include lack of territorial management, poor taxation, legal violations [11]. Proper ICT application and SA system could mitigate the problems by increasing manageability of territories where street vendors can be deployed.

New construction technologies are changing shape of cities today. Smart infrastructure and architecture are dominating the shift in the construction industry. In the Smart Cities Connect Conference and Expo in 2017, Skansa USA Chief Sustainability Officer Elizabeth Heider highlighted resilient design and sustainable construction as key aspects of how the construction industry can adapt to the needs of the Smart City initiatives in Santa Monica. A recent survey cited at ReadWrite notes that at least $60 \%$ of builders are now aware of Internet of Things (IoT) technologies and another $43 \%$ say that IoT will shape how they build in the future. By integrating IoT into the building process, including data capture and analytics, the new infrastructures built are future proof [12]. These facts prove increasing of density and granularity of urban infrastructure and leading role of ICT in construction.

Today in the most of inhabited areas such urban fixtures are identified only by appropriate maintenance organizations. But increase in city density and rapid technological changes lead to intensive modernization in the city infrastructure and require integrated approach in city management. The integrated approach in its turn requires coordination and uniform identification of the fixtures belonging to different organizations. SA for SC can provide here the following abilities:

- Uniform identification of the urban fixtures and places by street addresses, that is convenient for both service workers and ordinary people. That provides them an opportunity to refer to the urban fixtures in case of setting an appointment, accident, or just navigation;

- Information systems of different organizations can be easily integrated resulting in simpler coordination of their activities;

- Urban planning and management on city level can be simplified.

\section{B. Notation in Street Addressing}

Well-known SA systems are based on human understanding of address notation and meaning. Street addressing is an exercise that makes it possible to identify the location of a plot or dwelling on the ground, that is, to "assign an address" using a system of maps and signs that numbers or names the streets and buildings [2]. As was mentioned above, the current SA programs are not SC oriented. As a result, the address notation is also planned to be convenient for humans, but convenience for technical applications is not considered.

Such disregard often affects not only the external form of visual representation of the address, but also the internal structure of the address. For example, sequential addressing system in developing cities leads to increased fragmentation in addresses resulting in the raise of number of database records, that eventually increases memory consumption and reduces speed of search. This also leads to increase in the likelihood of error and the amount of work to maintain the system up to date. But the address notation can be optimized to be convenient both for humans and for representation in computer systems.

Development of international transportation and globalization processes enhance physical communication between countries and, therefore, increase tourism. Comfort of the city for tourists depends on people's ability to navigate within unfamiliar areas. Moreover, the size, changes in city structure and life style create favorable conditions for the citizens to know only part of their city. Such category of citizens is quite large now and sometimes they become guests in their own city when they visit unfamiliar areas.

SA system has a direct impact on convenience of navigation within the city. It should be mentioned that SA system should be easy to use by humans with no additional means. This requirement makes the city not only more comfortable, but also safer because it allows them to navigate quicker in case of emergency.

SA System should be uniformly applicable to the inhabited localities of all sizes, from smallest settlements up to huge mega-cities. The ability of SA System to be uniformly applied for settlements of wide range of sizes and types makes management of urbanization processes easier throughout the whole country. 


\section{Street Addressing as a Service}

As it was mentioned before, the SA's well-known purpose is to enable finding the required geo-object (or location) and navigate within the city. The nature of this purpose is its function. Thus, the SA can be considered as a service. At a simple look the SA could be just a labeling system for the urban geo-objects. This is a system's passive function. ICT introduces active approach to use the SA and make it the active service. One example of considering the SA as an active service is Location Based Services (LBS). In LBS SA lies under other services.

Conception of SC implies integration of city services. Being a fundamental, the SA system plays an important role in integration of these services and can be an underlying system for many of them. These facts demonstrate that the SA plays more and more significant role not only for humans, but also for functioning of different automated services and systems.

\section{A. Geocoding}

Geocoding is the process of converting addresses (like a street address) into geographic coordinates (like latitude and longitude), which can be used to place markers on a map, or position the map. Reverse geocoding is the process of converting geographic coordinates into a human-readable address [13].

Geocoding is a part of many systems that relate to urban management, navigation and similar applications. Quality of geocoding directly depends on the SA system. Geocoding is one of early and well-known geo-informatic services that relates to SA and can be considered even as a part of SA system. Indeed, single match between street addresses, location and geographical coordinates allows to state this.

\section{B. Geographic Information Systems}

A Geographic Information System (GIS) is a computer system for capturing, storing, verifying, and displaying data related to positions on Earth's surface. GIS can show many different kinds of map data, such as streets, buildings, and vegetation. This enables people to see, analyze, and understand patterns and relationships more easily [14]. This makes GIS the main computer application type for implementation of SA program or developing/maintaining of geographical services.

\section{Street Addressing Programs}

Rapid urban growth and expansion have made cities unmanageable, especially in the outskirts. Informal settlements have mushroomed. However, with the advent of e-commerce, increased efforts in building disaster resilience and advancements in geo-spatial technologies, street addressing methods and applications are undergoing a revolution today [3].

Studies of the World Bank show that there is a hundred of cities implementing the SA Programs [3]. There are three types of cities: (I) having a well-established SA system; (II) having a SA system that is not satisfies to the requirements;
(III) having no a SA System. Speaking strongly, well-established SA system in this statement means a SA system in their classical understanding, without orientation to the SC conception.

The SA Programs in their turn can be divided into two categories: establishing a new SA system and upgrading the existing one. Since the SA system is a city-wide one, changing or creating of SA system is expensive. Thus, the SA Programs should take into account both benefits and costs. Because the high cost of implementation of SA Programs, it makes sense to take into account their orientation towards SC early at the planning stage.

\section{Peculiarities of Modern Street Addressing System}

As it was shown above, the SC can be considered as socio-technical system. This implies that SA can be viewed from two perspectives - the use by humans and the use by technical solutions. Since the purpose of the SA is provision of information about location or point of delivery, in second case we can speak about perspective of use of it in Information Systems (IS).

Considering the quality of IS we can confirm that it depends on its constituent parts. This means that quality of SA contributes the whole quality of IS which uses it. Thus, reviewing the methodology of quality assurance for IS can help get clue how quality of SA for SC can be evaluated. The IS peculiarities can be assessed in accordance with socalled "-ilities": reliability, usability, safety, etc. [15]. Similar approach can be used to assess the SA peculiarities.

\section{A. Human Use Perspective}

The SA system should be able to provide services directly to people in convenient manner without special means (this requirement was considered above in this paper). There are cases when existing SA Systems are obsolete and no longer meet such requirements. For example, such problems occurred in Baku, Azerbaijan where old SA System was being upgraded by the SA Program [3].

Quality requirements to SA from human perspective are intuitively comprehensible because everybody has been using SA in their lives. Major SA "-ilities" from human use perspective are presented in the list below:

- Readability. Ability to read address notation (on the wall, postal envelope, package label and so on), remember it and retell it to other people. This ability relates both to one address and to range of addresses (for example several entrances on the same street). This feature also relates to the same requirements for foreign people. (Kabul Street Addressing Program supposes to use labels on 3 languages: Dari, Pashto, and English [5]);

- Navigateability. Ability for people to navigate within the unfamiliar areas of city without additional tools. This quality is especially important for tourists and city visitors. Generally, navigateability includes easy determination of current location, lo- 
cation of desired geo-object, and ability to plan route of movement;

- Addressability. Ability to assign address to wide range of geo-objects, including, but not restricted:

- Country, Region of the country / Province, City;

- District of the city, Plot;

- Thoroughfare (street, road, alley, canal, railway, ...);

- Dwelling, Complex Construction;

- Points: Entrance, Simple Construction, Installation, Urban Fixture, ATM, Historical Monument/Landmark, and so on.;

- Correctness. Basically this feature requires absence of the same addresses for different geo-objects and addresses with possible ambiguity, absence of "empty" addresses, that are pointing to nothing, and absence of geo-objects without addresses;

- Maintainability. Basically this feature requires ability to keep the system up to date with the lowest operational cost. Maintainability shall not impair all other qualities;

- Cost. This feature relates to capital cost of creating or upgrading the system. It can be decisive factor to start SA program or not.

\section{B. Information System Perspective}

The modern SA system is intended to be used in/by technical solution. Due to informational nature of SA, it is enough to consider use of SA in/by IS. Thereby it can be reviewed through IS perspective. Due to the fact that SA is considered as a service, its functionality can be realized as an ICT service (Web online service for example) providing data to other services (consumers). It is obvious that if SA service satisfies the principles of ICT quality, it will contribute total quality for the final IS.

The SA system implemented as an ICT service can be considered as a solution, containing software and hardware components. We can assume that SA system is a software solution whereas hardware can be placed behind the software. Hardware in this way can be considered just as a means to provide the possibility to run the software. Finally, we can assume that IS quality can be equal to software quality, and software quality assurance methodologies can be applied to provide quality of SA service. Requirements to the architecture and hardware can be formulated according to requirements of mission-critical systems (in this case emergency services can relay on it).

David Chappell selected three aspects of software quality: functional, structural, and process [16]. According to this division the following qualities can be highlighted:

- Functional quality, that make the product satisfying to the customer needs;

- Structural (or internal) quality, that is software structural quality refers to how it meets non-functional requirements;
- Process quality, that relates to the management, development, operating and maintaining (O\&M), and other processes.

Taking into account this reasoning of SA service quality from the ICT perspective, the following components can be considered:

- $\quad$ Functional quality - SA services software;

- Structural (or internal) - SA services software and hardware;

- $\quad$ Process quality - SA services software and hardware, maintenance, administration, and development processes.

As it was mentioned above, quality of software can be defined by different so called "-ilities": usability, reliability, availability etc. Theoretically, there may be a lot of "-ilities" [15]. But in practice many of them can be combined. The purpose of this research is to show the universal approach that could solve specific problems relating to SA for SC development. More deep analyses can be carried out, more detail level of "-ilities" can be determined for each practical case. Such research can be done within SA programs for different cases and form base of practical experience.

Software quality attributes and trade-offs are described in [17]. So, generally the quality of a SA service solution can be characterized by providing the following "-ilities" (these are additional requirements that should be combined with corresponding well-known software quality "-ilities" in each specific case):

- Reliability. The system should be correct, persistent, and consistent. Data should be updated according to changes in urban development and reflect actual situation;

- Efficiency. Efficiency of using the solution for easy use by humans and in integration with computer systems;

- Usability. Generally, this feature is the same as "Readability" from Human Use Perspective (see chapter above) but supplemented by abilities to be used by IS;

- Integrity. All SA parts regardless the size, type and location of an inhabited area should meet all SA requirements. It means that SA applied in such areas as village, town, city, city district should be built by the same methodology and meet all requirements;

- Maintainability. The same as "Maintainability" from Human Use Perspective (see chapter above) but supplemented by requirements for IS. For example data integrity might require implementation of maintenance operations according to Atomicity, Consistency, Isolation, Durability (ACID) principles;

- Flexibility. The system should be easy to use in any real-life application. "Flexibility" is the main feature that determines in which extent the SA could be used in $\mathrm{SC}$; 
- Testability. The system should be easy to check ICT provides additional possibilities to provide this feature. For example, sequences of house numbers can be tested according to their location along the street;

- Reusability. Ability to reuse parts of the addresses - could also relate to compactness of the addressing data because reuse reduces the data size within the SA system;

- Interoperability. Ability to be integrated with different services and systems. Generally, it could be considered as the same as "Flexibility";

- Survivability. Ability to keep qualities and remain intact as environment changes, i.e. reconstruction, emergency situations, natural disasters, and so on;

- Safety. The system should be safe to use. It also contains resistance to possible malicious activities, such as vandalism;

- Manageability. This feature is practically the same as one to measure/evaluate the SA peculiarities quantitative or qualitative, since it allows planning and monitoring SA related activities;

- Functionality. Ability to satisfy all human and IS needs according to the purpose;

- Scalability. Ability to be applied to inhabited places of any size;

- Portability. Could be considered as the same as scalability, but it relates more to different types of area and urban fabric;

- Expandability. Ability to add additional functionality;

- Supportability. Practically the same as "Maintainability".

All considered "-ilities" relate to all three components of David Chappell's aspects of quality: functional, structural, and process. At the same time all of them are tightly interdependent. For example, if SA is incorrect, it immediately becomes useless. Improving the readability can reduce addressability. Thus, trade-offs between the features should be achieved for each specific case. Specific cultural features of the area of SA program should also be taken into account.

\section{Vertical vs. Horizontal Referencing}

Classical SA systems have tree-like structure where leaf level is presented by house/entrance numbers and root is the country. As all elements of SA system have actual direct reference to the geo-objects located on the Earth, we can say that these references are vertical (for example country->district- $>$ city- $>$ street- $>$ house). As these references are obvious, we can consider them as explicit, or absolute references by their nature.

But there are also latent references presented in SA that can be named as relative or implicit. These references are between geo-objects grouped into structures where address/name/number of one object can give information about location of another one. The main type of such geoobjects is door numbers. For example, each door number provides information that a door with next number is located nearby. Streets or city districts can also provide such references if they are named according to their location. Because these references are between geo-objects of the same level, we can say that these references are horizontal.

Vertical references to the geographic location, in fact, relate to the SA's main purposes mentioned above. At the same time the horizontal references mainly determine the "Navigateability". For example, if somebody is on the street with numbered doorways he/she can obviously find the direction and estimate distance to the door with specific number located on the same street.

There are several other means to increase the navigateability that can include the directions to the geographic location or even culture specific features. The World Bank methodology proposes natural geographic objects, such as coastal line, rivers, mountains and so on as references determining starting points of numbering or naming of elements of the SA system [2].

Generally, there are three main components of classical SA that may refer to the geo-object:

- Regions, if they divide bigger area according to the cardinal points or other geographical features;

- Thoroughfares, if they are located along real geographical object, such as alley, boulevard, river;

- House/entrance numbers linked to the corresponding thoroughfare.

And these main components of classical SA can be referenced horizontally as the follows:

- Regions, if they logically divide bigger area according to some rule;

- Thoroughfares, if they are ordered according to some rule;

- House numbers if they constitute a sequence or ordered set.

Generally, the vertical reference helps find geo-object or location right away while horizontal reference helps travel. The SA systems are based on both vertical and horizontal references. SA for SC should provide these features in the same or greater extent. When planning SA special GIS applications could help to design the SA in way it has a the best possible navigateability by calculating names/ numbers/directions of SA elements and optimize their horizontal relations. Such research could have place in SA program but it is out of scope of current research.

Vertical and horizontal references of SA system relate to the structural component of David Chappell's aspects of quality. They are not related to addressing objects according to their physical elevation above or below to the ground. The growth of cities in height and depth (underground) is also an actual problem of addressing. But at the moment such problems relate to in-building navigation/addressing, while SA relates to objects accessible from the ground. At the same time expandable SA systems could include also inbuilding objects and physical vertical addressing. For exam- 
ple addressing by the height is seem actual in near future allowing automate delivery by the drones.

\section{Modern Postal Addresses}

Many people consider SA and Postal Addresses (PA) as the same conceptions. But this is not true. As it was stated above, purposes of SA system can be specified as determination of the location and the point of delivery. PA can serve the same functions, but not in all cases. PA are delivery-oriented conception and should be considered within Postal Services (PS).

Due to deep penetration of ICT into PS, their modern implementation should be also considered. Purpose of PS is to deliver the package to specific person, organization, or location. If the package is sent to specific person or organization, PS does not always need the street address to be stated as a destination. If destination uniquely identifies to whom or where the package should be delivered, it does not require to indicate the street address.

For example, the destination can be indicated as "Ministry of Education" of specific country. The PS can determine location of the ministry using underlying SA service or even provide delivery without determination of the address because the destination in this case is well-known. Another example is money transfer. It could be considered as a bank operation, but from PS point of view this operation can be considered as a delivery that does not need street address at all.

Modern PS should include ability to address one point of delivery by several methods. A requirement to use only one address for each delivery target introduces a limitation. Considering PS and SA as different services was very useful for Kabul, where the SA was broken and even ministries had no Street Addresses. This separation allowed addressing organizations by their names [4], [5].

So, the modern PS should be based on SA system and consume it as a service. And modern PS can be classified as a Location Based Service (at least its informational part) [18], [19] and use Geocoding (which was mentioned above) because it determines location by the information about the geo-object. Such vision of PS looks very convenient for SC, but the main point here is that the PS is not the same as the SA and strongly depends on it.

\section{E. Role of Street Addressing in inter-operability of systems}

SA information is part of data used in many of urban systems. There is number of SA applications that use addresses as key data (some examples are listed in description of "Flexibility" feature in chapter "Studies of the World Bank" below). Being ground data for services and systems, SA plays main role in inter-operation and integration of the systems. Inter-operation of the systems as the key component constituting a SC [9].

The feature of modern SA system to address each geo-object with one-to-one relationship allows considering the street address as an identifier (ID) for corresponding geo-object or as a part of the identification information. Moreover,
ID in this situation can be considered as a globally unique identifier (GUID) because full street address is globally unique. Therefore, the modern street address can be considered as a GUID and provide identification of geographical objects and constitute a reference system (role of primary/ secondary keys) at inter-system level in distributed IT solutions.

In terms of databases street address could be considered as type of the primary key. For integrated services and external referencing to geo-objects it could be considered as a secondary key. But it should be noted that this assumption must be confirmed at modeling stage for each specific solution because SA changes and features can affect the data integrity.

So, the modern SA has abilities that should not be easily shrugged off when designing architecture of ICT applications. Avoiding of non-required additional ID's can help reducing complexity of the solutions, database size, and communication traffic. At the same time such ability shows how important the SA's role for SC can be.

\section{F. Other Street Addressing systems}

Several attempts were made to develop an universal SA system or SA system for SC. These attempts were not successful by several reasons. First of all, as was mentioned above, SA and PA are different conceptions. Authors describe their systems as SA although their systems were based on requirements of PS. Another problem is attempt to build complex code for the address that reduces its readability.

For example the MappGuru that is positioned as an universal addressing system [20] looks like codification system based on requirements of PS. Building a SA on base of this solution most probably will show poor readability because long codes are not memorable, and poor navigateability because people navigate along the streets more convenient than according to proposed zoning. Anyway this is a brief observation and specific research should be implemented to evaluate this solution. Considering model seems a good tool for the evaluation this and other solutions.

There are number of standards that are relate to the SA. In [21] a number of national and international address standards are presented. This paper concludes that addresses do not have a single common feature but rather a 'family resemblance' in the Wittgenstein sense: a complicated network of overall and common similarities of detail. An overarching abstract address standard comprising different parts, each describing a specific set of these similarities would contribute towards a better understanding of these similarities and improve correct address usage and data exchange.

Considering model is not proposed as part of standard. But it could growth to become a practice, allowing evaluate of SA program for each specific case.

\section{Use CASES}

The system of peculiarities/features, proposed in this paper is built on experience of analyzing the studies and im- 
plementation of real SA-related projects. Overview of this experience seems to be useful supplement to the current study.

A. Studies of the World Bank

A very rich experience in studies and implementation of the SA programs for different cities worldwide was collected and published by the World Bank in [2]. The value of this study includes not only SA itself, but also its application to solve the actual urban problems. Many SA applications use ICT and form good use cases for research. A first look at the methodologies and experience, presented in [2] from perspective of considering model gives the following features:

- Readability. Is provided by codification and street signs installed;

- Navigateability. Is provided by dividing the city by zones, ordering of streets and doorways numbering;

- Addressability. SA programs assign a number to buildings (houses, places of business, facilities) and doorways. Addressing may be extended to urban fixtures such as public standpipes, fire hydrants, or waste transfer points;

- Correctness. Is provided by codification system and GIS;

- Maintainability. Is provided by organizational measures, such as regular inspections;

- Cost. Many SA programs are intended for poor cities. Thus cost plays here decisive role. At the same time optimization of the cost is actual for all cities;

- Reliability. Is provided by codification system;

- Efficiency. Considered mainly from human perspective;

- Usability. Considered mainly from human perspective;

- Integrity. Is provided by codification system;

- Flexibility. Using in different SA applications, such as civic identity, urban information (GIS, Geocoding), health care, street system management, household waste collection, inventory of municipal built assets, investment planning, improving the performance of the existing tax system, land tenure, slum upgrading, concessionary services, postal services, economic development, etc;

- Testability. Metric and decametric systems seems more testable than sequential;

- Portability. Application to cities with different shapes and landscapes;

- Reusability. Is provided by codification system and tree-like addressing (city, district, street, doorway);

- Interoperability. Can be used in GIS/Geocoding systems and integrate with different services and applications;
- Survivability. Metric and decametric systems are more survivable than sequential because doorway number correlate to their actual position;

- Safety. Is provided by installed or painted street signs and plaques;

- Manageability. Is provided by codification system;

- Functionality. Is provided by street signs and GIS/Geocoding;

- Scalability. SA programmes has been implemented for cities with population no more than $1.3 \mathrm{mln}$;

- Expandability. Is provided by integration with IS;

- Supportability. Is depends mainly on technologies of manufacturing of street plaques, installation/ painting street signs, and integrated technologies.

Several SA types and methodologies, presented in [2] can be a basis for their adaptation to some specific cases. So, the SA based on metric house numbering was used for development of the SA program for Kabul, Afghanistan.

\section{B. Case of Kabul, Afghanistan}

The SA program being implemented in Kabul is an outstanding example. The city SA was completely destroyed during the long war. The SA program covers area populated by $6.5 \mathrm{mln}$. and area of New City designed for additional 3 mln. inhabitants. The uniqueness of this case is concluded in fact that it is a huge city, capital that required implementation of the SA system from the scratch. But existing methodologies of building new SA system were developed for small developed cities. Kabul required specific SA considering different specific factors.

The methodology for the SA program was developed by the Ministry of Communications and Information Technologies (MCIT) within development of LBS. This demonstrates that development of ICT can be a driver for development of the SA program. As a result, the methodology of developing the SA system intended to be used in/by IS was elaborated.

Another challenge of development and implementation of the SA program in Kabul was deep difference in city infrastructure in center of city and slums within the outskirts. The SA should keep all its features at minimal cost when applying in slums. Specific challenge was integration of established SA of New City with new SA being developed for Kabul and Afghanistan as total.

A brief study of the Kabul case from perspective of considering model demonstrates specific features that should be emphasized:

- Readability. Use street signs in three languages: Dari, Pashto, English;

- Addressability. SA system supports addressing of Central Business District (CBD) area and slum area. Urban installations can also be addresses;

- Maintainability. Considers different approaches for CBD area and for slum area;

- Cost. Considers different approaches for CBD area and for slum area; 
- Efficiency. Considers support for humans and LBS;

- Usability. Considers support for humans and LBS;

- Testability. Metric system was selected for doorway numbering;

- Portability. Application to other Afganistan cities was considered;

- Interoperability. Integration with partially existing addressing and SA of New Kabul is considered;

- Survivability. Metric system was selected for doorway numbering;

- Safety. Addressing of slum areas was considered in depth because these areas are the most exposed to different threats;

- Manageability. Division to areas with different city fabric increases manageability;

- Scalability. Specific approaches allows to develop SA programme for this large city. Application for smaller places is supported also;

- Supportability. Slum areas were studied in depth to provide high level of Supportability.

The experience of SA program development for Kabul allowed focusing on integration of the SA with ICT.

\section{Case of Baku, Azerbaijan}

Baku is an example of city where former addressing system could no longer satisfy the modern needs. The study covers experience of working with new SA in Baku including processing of geographical data and building electronic maps for in-house GIS, online map, and Portable Navigation Devices (PND) within the project www.GoMap.Az (http:// www.gomap.az). Developers faced the problems of packing the SA information into data structures and automatically provide data quality control. The problem was rooted in a large number of entrance signs where digits are supplemented by the alphabetical letter. This significantly increases the data fragmentation that is a sign of fact that structural quality of the SA system is not enough.

After reviewing of SA standard applied [22] some conclusions were made. In terms of considering SA features, the SA program for Baku was elaborated with some trade-offs. Readability was selected as the primary SA feature, but other features were weakened. And it seems that root cause of current situation with the SA is necessity to transfer from the former SA system to a new one. Achievement of the best possible readability required keeping the sequential entrance numbering. But changes in economic situation have led to constant combining or splitting premises resulting changes in the city fabric patterns and finally ended in fragmentation in entrance numbers.

Thereby Baku SA program can be considered as a case where the SA was impacted by changes in economy and urban infrastructure. This means that the SA programs worldwide should consider development and implementation with the expectation of constant changes in urban infrastructure, because development of technologies is a global process. This requirement is also true for realization of SC conception. Focusing on $\mathrm{SC}$ in its turn can mitigate troubles that arise due to changes in city infrastructure.

\section{Commerce-Science Problem}

As it was mentioned before, the SA program is expensive and cities plan the ROI for a quite short period. Planning of SA for SC in one hand promises strategic advantages in the future, but in other hand introduces additional expenses. This problem is obvious. But there is another fundamental problem being discussed in Artificial Intelligence (AI) world but also relates to all modern technologies.

In his open letter signed by many prominent researchers and developers Max Tegmark shows that a small change in technology is available at the business level, which is interested in the speedy implementation of the solution without an in-depth laboratory analysis of the consequences. Meanwhile, a change in technology can have a tremendous impact on both human life and the environment [23]. One of examples demonstrating that the problem is actual for the SA, is a case with "what3words" service (https://what3words.com). The service was introduced and implemented without proper research. Avoiding proper peer-review before implementation resulted in criticism, negative feedback, and loss of market positions [24].

The root of problems with "what3words" service is that the service was introduced as a SA system, but it is actually an LBS. If the service was analyzed for SA features, the results would show that it cannot serve as an example of a good SA system. According to the proposed system of the SA pecularities, the three most poorest qualities of "what3words" service as a SA are: Addressability - because it can address only point geo-objects, Navigateability - because it does not support horizontal references, and Structural Quality, because the function that provides vertical references is complex and close (based on proprietary closed source codes), and there is no horizontal references making internal structure more solid.

At the same time, the convenience of service use and its advantages in specific use cases, as well as positioning it as an LBS, but not a SA, could give it a chance to become one of the integral parts of the SC services.

\section{Conclusion}

Rapid development of technologies leads to intensive changes that are available at the business level and has a significant impact to human life and environment. It means that all changes in technologies should be deeply researched before being implemented. Such well-known methodologies supported by established sphere as Street Addressing requires research for each specific case in context of available technologies and future trends. Role of Street Addressing in implementation of Smart City conception is considered primarily in provision of quality services for people and in integration of different city services. 
Simple system allowing assessment of Street Addressing qualities targeted to the future development is proposed in this paper. This system is considered as a starting point to carry out more deep research within the Street Addressing Programs. Experience in such research in several use cases would allow updating existing Street Addressing Program methodologies and making it possible to implement them for wide range of cities moving them closer to Smart City level.

\section{ACKNOWLEDGMENT}

The paper has been completed with the kind support of www.GoMap.Az project implemented by SINAM Ltd.

\section{REFERENCES}

[1] M.Finger, "Smart City - Hype and/or Reality?", IGLUS Quarterly, vol. 4, issue 1, June 2018.

[2] C. Farvacque-Vitkovic, L. Godin, H. Leroux, F. Verdet, R. Chavez, "Street Addressing and the Management of Cities", The World Bank, Washington DC, ISBN 0-8213-5815-4, 2005.

[3] S. Dharmavaram, C. Farvacque-Vitkovic, "Street addressing - a global trend", 2017 world bank conference on land and poverty, The World Bank, Washington DC, 2017.

[4] D. Gakh, "Analysis of World-Class Location Based Services, Survey Report of Kabul City, and Assessment on the requirements of the Numbering and the Addressing Systems", Ministry of Communications and Information Technology, Islamic Republic of Afghanistan, Kabul, 2014.

[5] D. Gakh, "Essentials of Street Addressing Programme for Kabu City", Ministry of Communications and Information Technology, Islamic Republic of Afghanistan, Kabul, 2014.

[6] V. Albino, U. Berardi, R. Maria Dangelico, "Smart Cities: Definitions, Dimensions, Performance, and Initiatives", Journal of Urban Technology, vol. 22, no. 1, 2015, pp. 3-21.

[7] F. Mosannenzadeh and D. Vettorato, "Defining Smart City. A Conceptual Framework Based on Keyword Analysis", TeMA, May 2014.

[8] H. Kopackova and P. Libalova, "Smart city concept as socio-technical system", 2017 International Conference on Information and Digital Technologies (IDT), Zilina, 2017, pp. 198-205, doi: 10.1109/DT.2017.8024297.

[9] P. Simpson, "Smart cities: understanding the challenges and opportunities", SmartCitiesWorld in association with Philips, Jan 2018.
[10] V. Moustaka, A. Maitis, A. Vakali, L. Anthopoulos, "CityDNA Dynamics: A Model for Smart City Maturity and Performance Benchmarking", WWW '20: Companion Proc. of the Web Conf. 2020, pp. 829-833, doi: 10.1145/3366424.3386584.

[11] "Do street vendors have a right to the city ?", Centre for civil society, IGLUS, October 2019.

[12] J. Brad, "Examining the Role of the Construction Industry in Building Smart Cities", IGLUS, Apr 2020.

[13] Google Developers / Geocoding API / Get Started, https://developers.google.com/maps/documentation/geocoding/start, accessed in April, 2020.

[14] National Geographic, GIS (geographic information system), https://www.nationalgeographic.org/encyclopedia/geographicinformation-system-gis, accessed in April, 2020

[15] J. Willis, S. Dam, "The Forgotten "-ilities"', SPEC Innovations, 2011.

[16] D. Chappell, "The three aspects of software quality: functional, structural, and process", David Chappell \& Associates, 2011.

[17] P. Berander, L.-O. Damm, J. Eriksson, T. Gorschek, K. Henningsson, P. Jönsson, S. Kågström, D. Milicic, F. Mårtensson, K. Rönkkö, P. Tomaszewski, "Software quality attributes and trade-offs", Blekinge Institute of Technology, 2005 .

[18] S. Steiniger, M. Neun, A. Edwardes, "Foundations of Location Based Services", University of Zurich, 2011.

[19] A. Edwardes, "Geographical Perspectives on Location for Location Based Services", LOCWEB '09, in Proc. of the 2nd International Workshop on Location and the Web, April 2009, article no.: 5 pp. 1 4, doi: 10.1145/1507136.1507141.

[20] V. Rwerekane, M. Ndashimye, "The MappGuru, a universal addressing system", SCA '18: Proc. of the 3rd International Conf. on Smart City Applications, October 2018, article no. 19, pp. 1-7, doi:10.1145/3286606.3286796.

[21] S. Coetzee, A. Cooper, P. Piotrowski, M. Lind, M. Mccart Wells, E. Wells, N. Griffiths, M. Nicholson, R. Kumar, J. Lubenow, J. Lambert, C. Anderson, S. Yurman, R. Jones, "What address standards tell us about addresses", South African Journal of Science, 2007, 103 (11), pp. 449-458.

[22] "Nəqliyyat infrastrukturu obyektlərinə adlarin verilməsi, daşinmaz əmlak obyektlərİnə ünvan nömrələrinin təyini, ünvan lövhələrinin yerləşdirilməsi”, Azərbaycan Respublikası standartlaşdırma, metrologiya və patent üzrə dövlət komitəsi, AZS 749-2013, 2013.

[23] M. Tegmark, "An Open Letter: Research Priorities for Robust and Beneficial Artificial Intelligence", https://futureoflife.org/ai-openletter, accessed in April, 2020.

[24] D. Gakh, "A review of street addressing systems within the realization of conception of Smart City", in Proc. Internet-Education-Science 2020, Vinnytsia, May 2020, pp. 96-98. 